\title{
Shaping the offshore decommissioning agenda and next-generation design of offshore infrastructure
}

Susan Gourvenec BEng, PhD, FIEAust, FICE

Professor of Offshore Geotechnical Engineering, Faculty of Engineering and

Physical Sciences, University of Southampton, Southampton, UK

(susan.gourvenec@southampton.ac.uk) (Orcid:0000-0002-2628-7914)

Many thousands of structures have been installed in the world's oceans to service the offshore hydrocarbon and renewable energy industries to provide energy resources to populations across the globe. Much of this infrastructure, particularly for hydrocarbon developments, has reached or is approaching the end of field life and requires decommissioning. Recent and future field developments, for both hydrocarbons and renewable energy, are setting up future waves of decommissioning activity. This paper presents recent developments in, and outlines the reshaping of, the offshore decommissioning agenda. The need for a multicriteria, multisector, transdisciplinary approach to informing offshore decommissioning and the design of the next generation of offshore infrastructure is demonstrated. Exemplar activities in this direction are described. The opportunity for society and governments to transform the agenda for decommissioning offshore infrastructure is put forward. Reduction in cost and risk and improved environmental outcomes of future generations of offshore infrastructure may exist for future generations in (global) society by resetting how decommissioning offshore infrastructure is carried out.

\section{Introduction}

\subsection{Overview}

The total global offshore decommissioning expenditure is expected to amount to US\$210 billion over the period 2010-2040 (Foxwell, 2016) and $1 \cdot 1 \mathrm{Mt}$ of infrastructure is expected to be brought onshore for reuse, recycling or final disposal from the UK and Norwegian Continental Shelves alone between 2016 and 2025 (Oil \& Gas UK, 2016). Existing offshore infrastructure, mostly associated with the hydrocarbon industry but increasingly with the offshore renewables industry, needs decommissioning in the near term or will need decommissioning in the coming decades, while the forecasted increase in offshore renewable energy production will set up waves of decommissioning into the future. Society should therefore ask the questions 'What is the optimal end-of-life solution for decommissioned offshore infrastructure for a given context?' and 'How can the range of decommissioning options inform the design of next-generation offshore infrastructure to ease the financial and environmental end-of-life burden of offshore assets?'

In this paper, the types of offshore infrastructure that need or will need decommissioning are initially introduced (Figures 1 and 2); the scale of the decommissioning challenge is illustrated in terms of both the number and scale of assets (see Figures 3 and 4); the definition of decommissioning is then analysed; the significance of including decommissioning and deconstruction as distinct stages of the infrastructure life cycle is emphasised (Figure 5); four decommissioning options are identified: (a) complete removal, (b) partial removal and relocation offshore, (c) partial removal and in situ decommissioning and $(d)$ partial removal and in situ decommissioning with augmentation (Figure 6); and reasons why complete removal is often the default option and barriers to adoption of alternative options are discussed. The need for a multicriteria, multisector, transdisciplinary approach to informing offshore decommissioning priorities and decisionmaking processes is set out and a conceptual framework to support the required approach is proposed (Figure 7); the paper culminates in a discussion of design of the importance of making decommissioning a key aspect of design and designing nextgeneration infrastructure to both optimise the full life-cycle cost of the asset and align design with the principles of the waste hierarchy (Figure 8). This discussion is extended by identifying potential exemplars of decommissioning good practice from other infrastructure sectors in which alternatives to complete removal are more widely adopted and an offshore exemplar of decommissioning and augmenting end-of-life infrastructure in situ (Figure 9). Finally, key findings and recommendations emerging from this research are consolidated as a set of recommendations in the concluding section of the paper.

\subsection{Types of offshore infrastructure}

A range of infrastructure is employed to extract hydrocarbons and harness renewable energy from the world's oceans, all of which will need decommissioning at the end of economic field life. To give an indication of the range of offshore infrastructure that needs to be, or will need to be, decommissioned in the future, a typology of offshore energy structures is given below and a selection of offshore infrastructure is illustrated schematically in Figure 1. Examples of offshore field architecture for a hydrocarbon and wind energy development are illustrated in Figure 2, showing a range of ancillary structures 

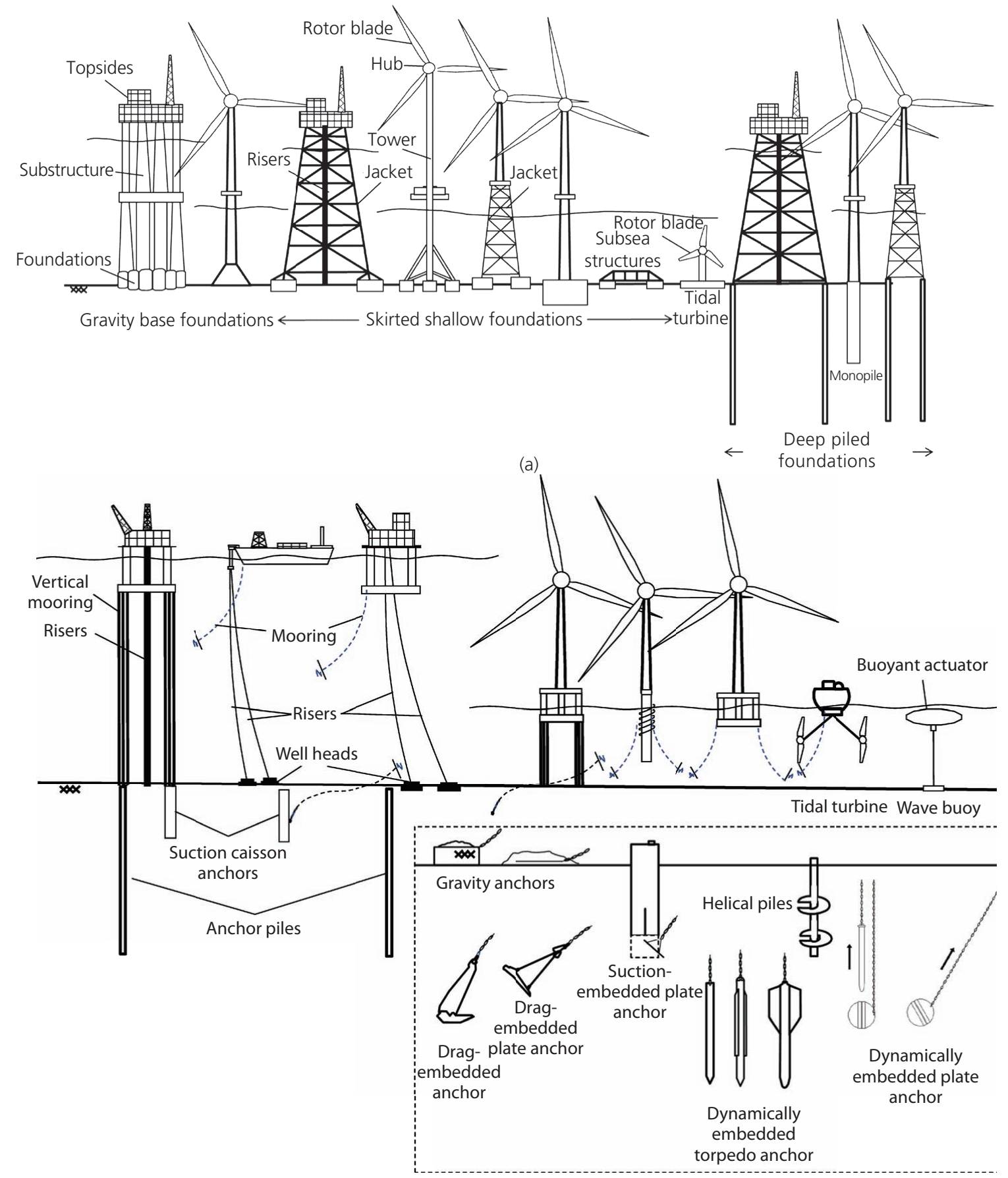

(b)

Figure 1. Examples of common offshore facilities and components: (a) fixed facilities - surface piercing and subsea - and foundations; (b) moored - buoyant and subsea facilities - and anchors

topsides - the part of the structure above the waterline and splash zone; may house equipment, processing facilities, working spaces and living quarters; can include facilities for oil and gas or renewable energy such as wind turbines nubstructure - a fixed structure founded on the seabed that supports the topsides (e.g. steel jackets, concrete gravity base structures, monostructures)

- buoyant platform - a floating facility with a mooring system to connect the structure to the seabed (e.g. floating production 


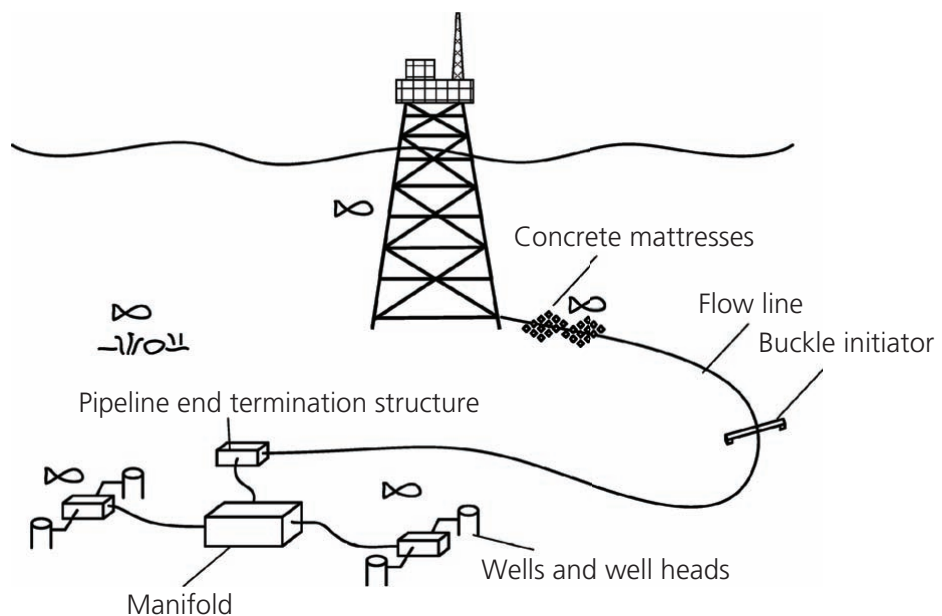

(a)

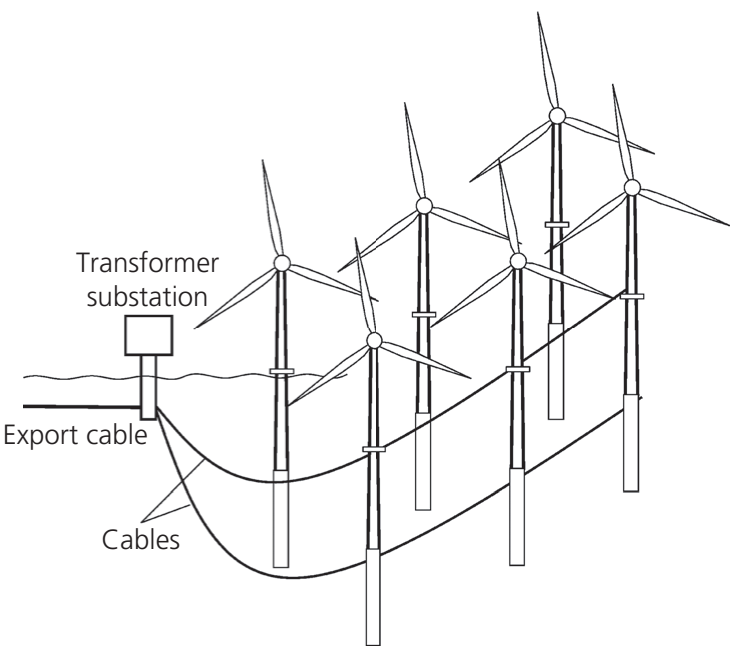

(b)

Figure 2. Examples of offshore energy development field layouts. (a) Offshore hydrocarbon development field layout (reproduced from Gourvenec and White (2017)); (b) wind energy development field layout

systems, semi-submersibles, tension leg platforms, wave and tidal generators)

- riser - a conduit for hydrocarbons or chemical injection between the topsides and the seafloor

- subsea structures (e.g. compressors, separators and wet trees) and supporting equipment (e.g. manifolds, pipeline end terminations, in-line structures, buckle initiators and riser support structures)

- foundations and anchors for supporting or mooring facilities and subsea structures (e.g. shallow foundations, piles, caissons, drag anchors)

vipelines - conduits for transporting hydrocarbons, water or injection chemicals around the seafloor between wells and the processing facility (e.g. infield flow lines, spools, jumpers, export pipelines)

n cables and umbilicals - for transmission of power or chemicals to wells or facilities

- ancillary structures (e.g. concrete mattresses, rock blankets to stabilise on-seabed equipment and infrastructure)

- wells - plastic and steel casings grouted into the seabed for reservoir access.

\subsection{Size and scale of offshore infrastructure}

Offshore structures are designed to provide a diverse range of functions, and their size and scale are equally diverse. Offshore oil and gas topsides and substructures can be hundreds of metres in edge length or height. Considering as an example oil and gas topsides and jacket structures in the North Sea, topsides have mass ranging from 70 to $53000 \mathrm{t}$ with an average of $4300 \mathrm{t}$ and steel substructures between 100 and $45000 \mathrm{t}$ with an average of $3500 \mathrm{t}$ (Arup, 2014) (Figure 3). Subsea structures perform a variety of functions that dictate their scale, and their edge length may range from a metre or so to tens of metres.

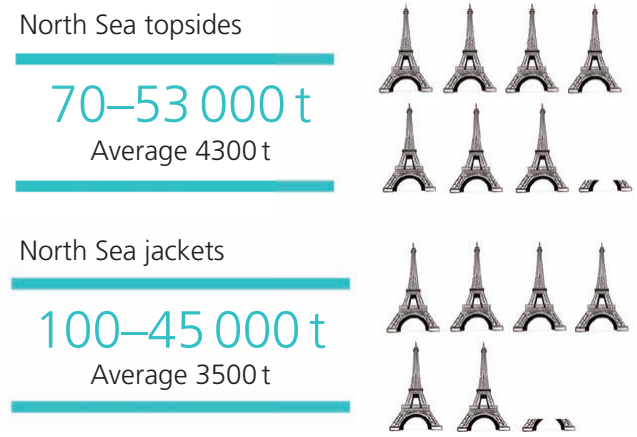

Figure 3. Example of scale of infrastructure - North Sea oil and gas topsides and jackets

Offshore wind turbines have evolved from structures with hub height and rotor diameter of less than 20 to over $100 \mathrm{~m}$ to facilitate the increase in yield from tens of kilowatts up to several megawatts (World Energy Council, 2016). Currently, the largest wind turbines have a maximum capacity of $9 \mathrm{MW}$ and rotor diameters up to $180 \mathrm{~m}$ (WindEurope, 2017). With improvements in blade technology and controllability of offshore wind turbines, the continued increase in wind turbine size to facilitate increase in power output is not inevitable. The size of fixed offshore wind structures is practically limited by a water depth of less than $50 \mathrm{~m}$ because of allowable bending deflection of the structure up to the transition piece. Tripod and jacket founded turbines can overcome this limitation to some extent but are not yet commonly adopted technologies. The world's first and only floating wind farm (Hywind) is installed at $100 \mathrm{~m}$ depth of water, $25 \mathrm{~km}$ from the shore, but with technology that has the potential for deployment at any water depth, with an appropriate mooring, at any distance 
from shore, potentially increasing the size of the structure and anchors. The second floating wind project is due to come online in 2018 at Kitakyushu, Japan (GWEC, 2017).

Offshore tidal turbines and wave energy buoys are too limited in number to present typical dimensions, but those in existence or development have a rotor or buoy diameter up to $20 \mathrm{~m}$ and are sited nearshore in relatively shallow water.

\subsection{Scale of the offshore decommissioning challenge}

Globally, offshore oil and gas infrastructure amounts to thousands of platforms, a range of seabed structures, many thousands of kilometres of pipeline and tens of thousands of wells (see Figure 4). For example, the Gulf of Mexico hosts almost 3500 facilities (Maslin, 2016); an excess of 1700 offshore installations are sited in South East Asia, nearly half of which are older than 20 years and due to be decommissioned (CIL NUS, 2013); and over 600 fields are expected to cease production in the AsiaPacific in the next 10 years (Wood Mackenzie, 2016). In Australia, there are 110 offshore oil and gas platforms and subsea structures, with many approaching the end of production life, and only a small number of early projects have already been decommissioned (Cullinane and Gourvenec, 2017); and more than 550 platforms and subsea structures currently installed in the North Sea (RAEng, 2013). Figure 4 illustrates the scale of the global offshore decommissioning challenge, showing the number of facilities currently in operation across the globe, which will inevitably require decommissioning.

Offshore decommissioning costs of the oil and gas infrastructure in the North Sea alone are forecast at $£ 47$ billion (US\$66 billion) to 2050 - with an uncertainty of $\pm 40 \%$ (Oil and Gas Authority, 2016), and the total global offshore decommissioning expenditure is expected to amount to US\$210 billion over the period 2010-2040 (Foxwell, 2016). Considering the North Sea context, only $12 \%$ of commissioned oil and gas infrastructure has been decommissioned to date (Arup, 2014), and 100 platforms are expected to be decommissioned on the UK and Norwegian Continental Shelves over next 10 years - along with 1800 wells and $7500 \mathrm{~km}$ pipeline (Oil \& Gas UK, 2016).

In terms of renewable energy facilities, more than 2500 wind turbines are currently installed in the North Sea (WindEurope, 2017). Worldwide, a total of $18814 \mathrm{MW}$ of offshore wind

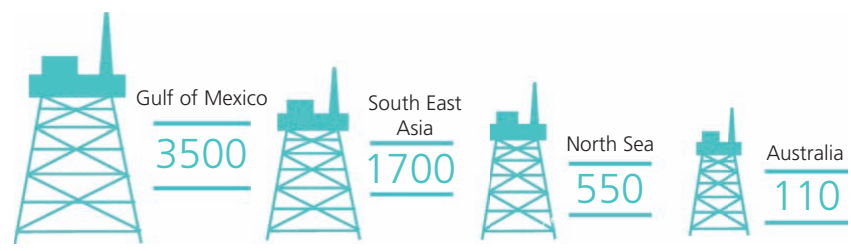

Figure 4. Scale of the global offshore decommissioning challenge number of operating offshore oil and gas facilities by region capacity is installed in 17 markets around the world (GWEC, 2017) and, with capacity rising exponentially each year, sets up a significant future wave of decommissioning.

The younger offshore renewables industry is perhaps more focused on commissioning new projects than decommissioning, but projects are beginning to approach the end of operational life. The first offshore wind energy decommissioning project took place in 2016, for the Yttre Stengrund, offshore Sweden (MarEx, 2016), followed by Lely, offshore Netherlands (Russell, 2016) and Vindeby, offshore Denmark - and the first offshore wind farm ever built (Lempriere, 2017).

Decommissioning cost estimates for offshore renewables are cited to range from $£ 40000 / \mathrm{MW}$ in the UK - leading to UK liabilities of $£ 288$ million for construction up to 2020 (CCC, 2010), to more than double that per megawatt in the USA (Kaiser and Snyder, 2012). With in excess of $18000 \mathrm{MW}$ of currently installed offshore wind power (GWEC, 2017), this gives a future global decommissioning price tag of $>$ US\$2 billion for currently installed offshore renewable capacity alone. Estimated costs for decommissioning offshore wind projects will inevitably vary going forward as the number of installations, architecture, technology and locations of projects change, and experience of the actual cost of decommissioning offshore wind projects can inform predictions. Forward-looking studies addressing design considerations to ease removal of offshore wind farms at the end of their production life exist (e.g. Topham and McMillan, 2017) and, while these may not provide definitive answers to the current uncertainties, provide a platform for highlighting the diversity and scale of the challenge and the potential wins to be achieved.

The scale of the offshore decommissioning challenge is increasingly well understood - what is less well understood is the life-cycle effect of decommissioning alternatives and the evidence base and decision tools for determining which option realises the optimal outcome and in which contexts. These aspects, along with consideration of how these decisions play into transforming the offshore decommissioning agenda for future generations and design of the next generation of offshore infrastructure, are the subject of the remainder of this paper.

\section{Offshore infrastructure decommissioning alternatives}

\subsection{What is decommissioning?}

Before exploring alternatives for offshore decommissioning, it is useful to consider what decommissioning offshore infrastructure actually means. In the offshore engineering sector, various terms are used interchangeably to mean decommissioning - these include 'abandonment', 'retirement' and 'removal' - however, there is no formalised and universal definition of 'decommissioning' - or the alternative terms widely used to indicate decommissioning. Dictionary definitions of decommissioning include 'withdrawal from service', 'to make inoperative', 'planned shut-down or removal of a 


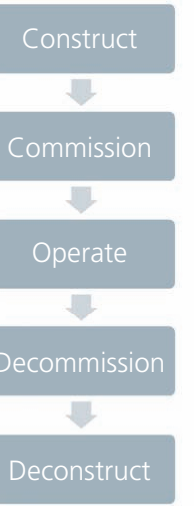

Manufacture and installation of facility Pre-commissioning testing

Certification that the facility meets requirements to start operation

Operation of a facility (to produce oil and gas)

Certification that the facility meets ments to cease operation (i.e. the reverse of commissioning) facility (i.e. the reverse of construction)

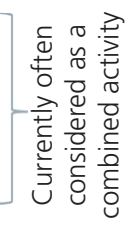

Figure 5. Stages of the life cycle of offshore infrastructure

structure or facility from operation or usage' or 'to remove or retire from active service'. In the offshore context, decommissioning is usually taken as synonymous with complete removal of the infrastructure to leave the seabed as it was before the development. However, are or should 'decommissioning', 'abandonment', 'retirement' or 'removal' be different activities or the same thing? This question is considered in the following discussion.

One approach to considering this question is to look at the stages of the life cycle of offshore infrastructure (Figure 5). The life cycle starts with a construction stage in which the facility is manufactured and installed at site; precommissioning testing then follows, culminating in commissioning in which the facility is certified to meet the requirements to start operation. The operational stage then commences that will include maintenance, renewal and component replacement and may include a period of life extension of the facility following the end of the initial design life and which will determine (or delay) when decommissioning is required. Ambiguity arises in the latter stages of the life cycle where 'decommissioning' is commonly but not definitively taken to include making the facility safe at cessation of production and dismantling, removing and disposing of the infrastructure. For balance, the latter stages of the life cycle should mirror the initial stages of commissioning and construction - that is, decommissioning and deconstruction - and should be treated as separate stages.

Considering decommissioning as activities to achieve certification that the facility meets requirements to cease operation provides a pathway to alternatives to complete removal of infrastructure. The final stages are inevitably linked, and the activities required for decommissioning will be dependent on the choice of what will happen next - that is, whether infrastructure be removed, relocated or left in situ. Figure 6 illustrates various alternatives for decommissioning offshore infrastructure.

\subsection{Complete removal}

The current base case for decommissioned offshore infrastructure worldwide is complete removal and disposal onshore through

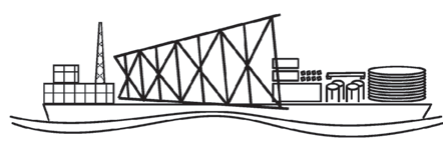

$\underset{-1 \text { roll }}{\infty}$

Complete removal
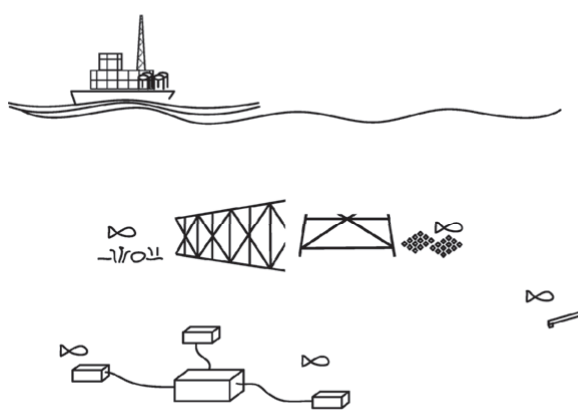

Partial removal and in situ decommissioning

$\infty$

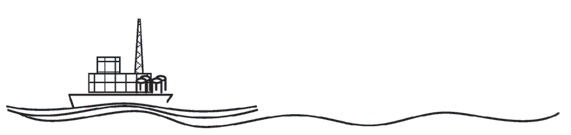

$\stackrel{\infty}{\text {-1rO这 }}$

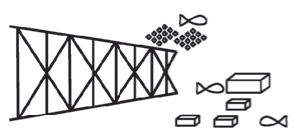

Partial removal and relocation offshore
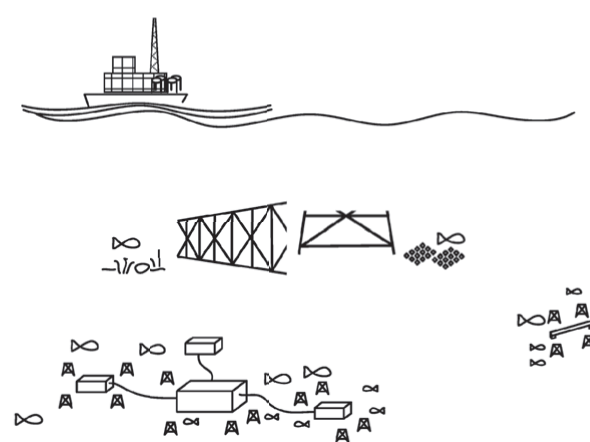

Partial removal, in situ decommissioning and augmentation

Figure 6. Options for offshore decommissioning (after Gourvenec and White (2017)) 
recycling or landfill. International law (IMO, 1989) makes provision for alternative fate or use of offshore structures provided that due consideration is given to safety of navigation, rate of deterioration, risk of structural movement, environmental effects, costs, technical feasibility and risks of injury associated with removal. However, national or state laws tend to recommend complete removal as the base case. In the North Sea, complete removal is currently required by the Convention for the Protection of the Marine Environment of the North-East Atlantic, or the 'OSPAR' agreement (OSPAR Commission, 1998) - so-called as the legislation combines aspects of the Oslo Convention for dumping waste at sea and Paris Convention on land-based sources of marine pollution. Complete removal is a heterogeneous activity, with numerous approaches, drivers and constraints depending on the field architecture, location and available technology.

\subsection{Partial removal and relocation offshore}

A precedent exists for removal and relocation to another offshore location - most well known through the US 'rigs-to-reefs' programme (BSEE, 2018) and also adopted for various projects across Asia. However, even removal for relocation involves expense and risk and can damage the marine ecosystem that developed around structures during the production life. Rigs-toreefs programmes are controversial, and debate regarding their validity is ongoing in most regions (Jørgensen, 2012; Macreadie et al., 2011).

\subsection{Partial removal and in situ decommissioning}

An end-of-life option of leaving all or part of the infrastructure in situ - that is, without relocation - has the benefit of reducing the requirement of large vessels for removal. This leads to a reduction in cost and risk, as well as leaving the established marine ecosystem intact (Claisse et al., 2014, Macreadie et al., 2011; McLean et al., 2017).

A precedent exists for in situ decommissioning, for example, of pipelines, even in the North Sea since pipelines are not explicitly covered in the OSPAR agreement. If pipelines are to be decommissioned in situ, a comparative assessment is required (to be provided by the operator to the regulator) to show that in situ decommissioning is the optimal outcome from safety, environmental, technical, societal and economic perspectives. Wells must be decommissioned in situ - and constitute a significant proportion of the offshore decommissioning scope. In the North Sea, the liability for the wells lies with the operator of the field in perpetuity. Some structures can be decommissioned in situ in the North Sea through the derogation clause under OSPAR, which provides for structures above a weight threshold of $10000 \mathrm{t}$ in air, and therefore potentially technically too risky to remove, to be decommissioned in situ. Again, a comparative assessment is required to show that complete removal options are not feasible. While derogation can permit some heavy structures to be decommissioned in situ, the basis of the decision is whether removal is too risky - rather than whether decommissioning in situ may be the optimal end-of-life solution - for example, having a beneficial environmental impact, or least (complete life cycle) environmental impact.

\subsection{Partial removal, in situ decommissioning and augmentation}

There is also the option of augmenting oil and gas infrastructure left in situ after decommissioning with engineered artificial reef modules to optimise the marine benefit, for a potential further future use, and enhance stability in the afterlife (Gourvenec and Techera, 2016; Gourvenec and White, 2017).

The choice of decommissioning option will ultimately depend on what is legally permissible and technically feasible and also what is desirable from an environmental, economic and societal perspective. No single solution will fit all cases, and the optimal decommissioning decision for an offshore development will depend on multiple variables. These variables include, for example, the development architecture and infrastructure; the nature of the offshore environment, ocean users and other users in the region and national or regional policy covering the area in which the infrastructure to be decommissioned is located. Given the number of variables involved, determination of the optimal decommissioning option and the decommissioning strategy to deliver that option requires a multicriteria, multisector, transdisciplinary framework to identify and evaluate the relative merits of different options against a set of contextual specific criteria.

\section{Multicriteria, multisector, transdisciplinary approach to informing decommissioning}

Current decommissioning plans for offshore developments typically involve a comparative assessment to assist in complex trade-offs between safety, environmental, technical, societal and economic impacts. Alternative processes for a particular outcome or end-of-life outcomes are assessed against preselected criteria that can then be ranked and compared. The intended outcome is a transparent selection process from the range of decommissioning options outlined earlier. Issues can arise - as with any analysis if the input data are of poor quality - for example, if data are incomplete or biased towards particular stakeholders. A consistent industry-wide, or legislated, approach defining the framework and methodology for gathering and weighting data gathering across the sector could assist in clarifying expectations and streamlining the process for operators and regulators.

Currently, complete removal is the default option. Comparative assessment is used to decide on the most appropriate decommissioning plan for complete removal. Alternatives to complete removal are assessed only if derogation from current legislation is sought - that is, if complete removal is not being proposed. Shell UK recently used a participatory multicriteria decision analysis approach as part of the comparative assessment for the Brent Field decommissioning plan, which amounts to several hundred pages and covers a range of activities (Shell, 2017). 
Significantly, comparative assessment is typically used to determine the optimal method of complete removal. No process exists to determine whether complete removal is the optimal decommissioning option for the vast majority of decommissioned offshore infrastructure in the North Sea. Aside from the absence of opportunity for the process, the evidence base is insufficient to assess if complete removal and recycling or disposal onshore is the optimal outcome. Complete removal is simply not compared with offshore decommissioning alternatives for the vast majority of developments.

Comparative assessment to identify the best strategy for delivering complete removal of a decommissioned asset is insufficient - rather a decommissioning framework is needed that explicitly challenges the default option of complete removal by undertaking comparative assessment of the different decommissioning options (Figure 6) to select the most appropriate decommissioning option. A second comparative assessment can then be undertaken to identify the best strategy for delivering the chosen decommissioning option to be undertaken.

The challenge for furthering the offshore decommissioning agenda is development of the scientific evidence base to justify the various alternatives - including and beyond complete removal; development of the technical innovations to facilitate those alternatives with minimum cost and risk; development of decision tools to determine the optimal solution for a given scenario - accounting for inputs across all sectors, stakeholders and the community - and development of processes and governance that provide clear and transparent pathways for decommissioning.

An example of a high-level multicriteria, multisector, transdisciplinary decision framework to inform on decommissioning offshore infrastructure, providing a conceptual starting point for the required evidence base, is illustrated in Figure 7. The framework is intended to inform across all decommissioning outcomes (from $100 \%$ removal to $100 \%$ in situ decommissioning) and for all infrastructure types (across fixed and floating structures, subsea infrastructure and pipelines and wells). The engine of the framework is a bank of weighted evidence to assess whether infrastructure can be removed, relocated or left in situ and determine the impact of the spectrum of decommissioning options, reflecting multiple disciplines (across the physical, biological and social sciences) and a diversity of opinions (across sectors and the general public).

In terms of the bank of weighted evidence - whether a structure can or should be removed - will be informed by questions relating to marine science $(\mathrm{M})$, such as 'What are the impacts (positive and negative) during removal on the environment?'; engineering (Eng), 'Does the technology exist to remove it and dispose of it safely?'; economics (E), 'How much will it cost to remove, and who is paying/liable?'; societal impact (S), 'Is there social acceptance? How can stakeholders be better informed on the marine science, engineering and economic aspects?' and law, policy and governance (L), 'Does law support this option?'
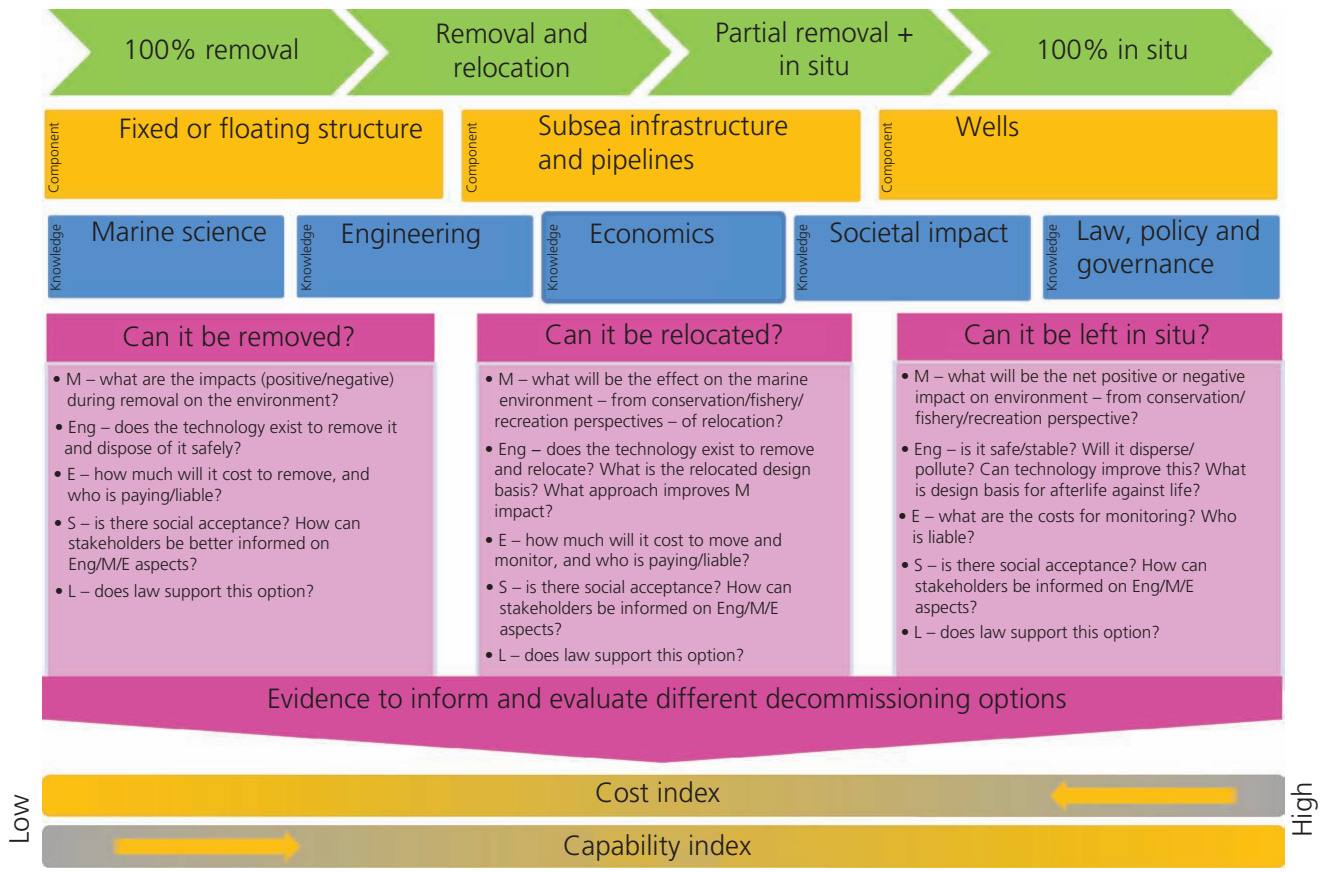

Figure 7. A conceptual decision framework for supporting improved offshore decommissioning decision-making (Gourvenec, 2017). E, economics; Eng, engineering; L, law, policy and governance; $M$, marine science; S, societal impact 
Whether a structure can or should be relocated will also be informed by questions relating to multiple disciplines. From a marine science $(\mathrm{M})$ perspective, 'What will be the effect on the marine environment - e.g. from conservation, fishery, recreation perspectives - of relocation?'; from an engineering (Eng) perspective, 'Does the technology exist to remove and relocate? What is the relocated design basis? What approach improves the marine science impact?'; from an economics (E) perspective, 'How much will it cost to move and monitor, and who is paying/ liable?'; from a societal (S) perspective, 'Is there social acceptance? How can stakeholders be better informed on the marine science, engineering and economic aspects?' and from a law, policy and governance (L) perspective, 'Does law support this option?'

Whether a structure can or should be left in situ will also be informed by a range of questions relating to multiple disciplines. For this scenario, from a marine science (M) perspective, questions such as 'What will be the net positive or negative impact on the environment from a conservation, fishery or recreation perspective?'; from an engineering (Eng) perspective, 'Is it safe and stable? Will it disperse and/or pollute? Can technology improve this? What is the design basis for the afterlife compared with the operational design life of the structure?'; from an economics (E) perspective, 'What are the costs for monitoring? Who is responsible and liable?'; from a societal (S) perspective, 'Is there social acceptance? How can stakeholders be better informed on the marine science, engineering and economic aspects?' and from a law, policy and governance (L) perspective, 'Does law support this option?'

These are not intended to be an exhaustive set of questions, but suggestions to give an indication of the extent of evidence base required to make informed decisions about different end-of-life options for offshore infrastructure.

Development of the evidence base requires consolidation of existing knowledge and future research across the physical, biological and social sciences. The scientific challenge must be addressed in order to develop smarter ways of decommissioning existing and future offshore infrastructure to minimise cost, risk and environmental impact of the end-of-field-life fate of offshore structures - either offshore or onshore - and maximise societal benefit.

\section{Recent developments and reshaping of the offshore decommissioning agenda}

Recent national and regional strategy documents summarise the current state of knowledge, research and practice identifying the scale of the offshore decommissioning challenge. These have tended to focus on identifying the size of the challenge (Arup, 2014; CIL NUS, 2013; Dret, 2008; Oil \& Gas Authority, 2016; RAEng, 2013; Wood Mackenzie, 2016); the environmental impact, particularly marine science aspects of removing existing offshore infrastructure (Advisian, 2017; CPA, 2011; Wamsi, 2016) and readiness of the industry supply chain for removal-based offshore decommissioning activities (Nera, 2016; Oil \& Gas Authority, 2016).

These documents highlight the need for research addressing technical challenges of removing often vast and aged infrastructure from harsh environments, the potential environmental impact of removal and disposal, the huge cost, shared between the operator and government (ultimately the taxpayer) and the uncertainty in predicting the actual cost, the many and often conflicting priorities of stakeholders and the lack of clarity in interpretation of the law.

Research and commercial investment has been made to improve engineering capability for removing structures (e.g. MarEx, 2015), for removing and relocating offshore (Claisse et al., 2014; Macreadie et al., 2011), for in situ decommissioning (Gourvenec and White, 2017), for augmenting with artificial reef modules (Scott et al., 2015) or for appraising the suite of options (Chandler et al.. 2016; Ekins et al., 2005; Fowler et al., 2014). However, few studies have addressed the extrapolation of material and structure integrity from a 50-year design life to in perpetuity (Melchers, 2006; Paik and Melchers, 2014; Rosen et al., 2015).

Marine science research has reported the beneficial effects of offshore infrastructure on marine ecosystems in terms of abundance and diversity of habitat and fish (Claisse et al., 2014; McLean et al., 2017; Scott et al., 2015), and programmes in the North Sea such as Influence of Man-made Structures in the Ecosystem (Insite, 2018) and Living North Sea Initiative (http:// www.living-north-sea.eu/) provide valuable marine science data on the effect of man-made structures on a specific marine environment. Less data are available on the long-term potential environmental risks of infrastructure left offshore in perpetuity (Reisser et al., 2013). Less still are available on the true life-cycle environmental impact of the different decommissioning options identified in Figure 6 and described earlier.

The direct financial cost of current removal-based decommissioning has been assessed by governments, industry bodies and consultants (Foxwell, 2016; Nera, 2016; Oil \& Gas Authority, 2016). Potential reduction in cost from alternative decommissioning options is less well reported and has not been widely considered outside of the USA where the rigs-to-reefs programme provides a regulated framework allowing for offshore disposal of offshore infrastructure. The cost and opportunity for nations of alternative decommissioning options, in terms of job creation, future investment and development of expertise for export, are also yet to be quantified.

Stakeholder engagement is carried out for individual decommissioning plans and in cases as part of government initiatives (Wamsi, 2017). The broader and deeper societal implications of different decommissioning options have yet to receive substantial attention although there is much to be learnt from the effect of intervention and changes in policy and practices on coastal communities (Richert et al., 2015; Rogers and Burton, 2017). 
The base case for complete removal is borne out of law to protect against sea dumping (OSPAR Commission, 1998) and needs revisiting to enable alternative offshore decommissioning options more routinely. Opportunities exist within current international law (IMO, 1989) for repurposing offshore infrastructure if it can be shown that leaving in place will have no significant detrimental effect on the environment or other ocean users or has a lesser economic and environmental life-cycle impact than alternatives. However, the practicality of relying on these provisions is limited by local regulators (Techera and Chandler, 2015). Tax regimes and future legal liability for assets decommissioned in situ also require attention to provide clarity for operators and regulators (Parenti et al., 2006).

A key finding from a review of decommissioning literature conducted as part of this research is that insufficient scientific evidence exists to determine which of the decommissioning options (Figure 6) are the best solution in any given context - that is, either that the current base case of complete removal and disposal onshore is the best solution or that relocation or leaving infrastructure in situ, potentially augmented with artificial reef modules, is the best solution.

The scientific evidence base is required to underpin a decision framework to inform on and enable the most appropriate decommissioning option for a given location, marine environment and field architecture to deliver minimum cost, risk and environmental impact.

A strategic plan is required to develop the evidence base and decision framework, achieve agreement on adoption of a consistent approach across the sector and gain public acceptance of the approach.

\section{Design of next-generation offshore infrastructure}

Once alternative decommissioning options are more routinely enabled, attention can be focused on designing for the next generation of offshore infrastructure, whether for oil and gas, renewable energy, seabed mining, aquaculture or other uses, within the new boundary conditions.

The EU waste framework directive waste hierarchy (EC, 2008), illustrated in Figure 8, is a useful guide to assist design such that maximum practical benefits are extracted from products and the minimum amount of waste is generated at the end of the asset life. The waste hierarchy is used in comparative assessment to inform evaluation of different decommissioning strategies or in the case of legal derogation being sought to leave a structure in place if over the threshold weight limit or for pipelines. Significantly, complete removal remains the default decommissioning option; therefore, comparative assessment is not routinely used to compare decommissioning options. Considering end-of-life fate at the design stage could lead to greater efficiencies. A key aspect of the waste hierarchy is that the

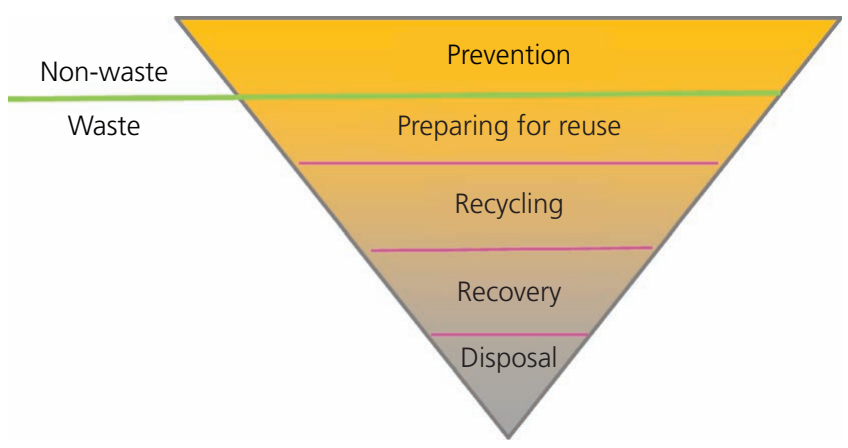

Figure 8. Waste hierarchy (Gourvenec, 2017) (redrawn from Defra (2011))

solutions are resource efficient and actions are avoided that simply shift negative impact to another stage. Consideration of the entire life-cycle consequences of all decommissioning alternatives can minimise the risk of shifting negative impact across sectors and stakeholders.

No industry-wide statistics are available regarding the fate of decommissioned offshore infrastructure, in terms of the percentages reused, recycled or sent to landfill. Achievable rates of reuse and recycling depend on the field architecture (see Figure 2). For example, the Shell Brent Decommissioning Plan (Shell, 2017) targeted 97\% recycling for topsides, but did not set similar or recycling targets for those components brought to shore, such as the steel jacket structure (see Figure 1); while Hess (2014) reported $48 \%$ reuse, $49 \%$ recycling and 3\% landfill in the close-out report of decommissioning of the Fife, Fergus, Flora and Angus fields that comprised subsea architecture tied back to a floating production, storage and offloading facility.

Design lessons can potentially be learnt from onshore exemplars such as the automotive industry, with similarities to the oil and gas industry in terms of the necessity to deal with large volumes of hazardous and contaminated materials at the end-of-life phase of assets. In the automotive industry, end-of-life vehicles contribute $8 \mathrm{Mt}$ of waste per annum just from within the EU - in comparison to $1 \cdot 1 \mathrm{Mt}$ of infrastructure that is expected to be brought onshore for reuse, recycling or final disposal from the UK and Norwegian Continental Shelves between 2016 and 2025 (Oil \& Gas UK, 2016). The automotive industry has undergone a transformation in design philosophy that has seen the industry reduce its landfill waste by $90 \%$ since 2000 . Vehicles are now increasingly designed to be recycled at the end of life, and current EU legislation requires $95 \%$ of a car to be recycled when scrapped (EC, 2000). Furthermore, the end-of-life vehicles directive (EC, 2000) not only sets recycling targets but also pushes producers to manufacture new vehicles without hazardous substances (e.g. lead, mercury, cadmium and hexavalent chromium), thus promoting the reuse, recyclability and recovery of vehicle components and materials at the end of vehicle life. 
In the context of decommissioning offshore infrastructure, notwithstanding stretch goals for recycling, opportunities can be sought to reduce the amount of energy and materials being used in fabrication, installation, life-cycle asset management and decommissioning and to develop materials and processes that reduce the burden of late-life management and decommissioning.

Moving up the waste hierarchy to 'reuse', various generic proposals have been put forward for alternative use of decommissioned offshore infrastructure (RSA, 2015). The cost and risk of maintaining and running an aged offshore facility often make the economics of alternative use post-decommissioning impractical. Reefing options are perhaps the exception - and are varied, from nearshore recreational diving and fishing amenities to deepwater tourist or commercial fishing sites or to protected areas for habitat growth and fish production to stimulate the marine environment beyond the protected areas. Stepping out further, the question can be posed that if a structure decommissioned in situ poses less environmental impact than disposal onshore and does not affect other ocean users, is in situ decommissioning a better outcome even if it does not create an ecosystem? Clearly, questions of longterm risk in either the onshore or offshore scenario are critical to decision-making. Reefing or other offshore disposal options for decommissioned offshore infrastructure could be considered in the context of the $8 \mathrm{Mt}$ of plastic that ends up in oceans annually as a result of everyday trash, projected to increase by tenfold over the next decade (Jambeck et al., 2015) - in comparison to the $1.1 \mathrm{Mt}$ of offshore infrastructure expected to be decommissioned on the UK and Norwegian Continental Shelves between 2016 and 2025 (Oil \& Gas UK, 2016).

Lessons can potentially also be learnt from the nuclear, chemical and mining sectors. The nuclear industry is facing a significant decommissioning challenge and, similar to the offshore hydrocarbons industry, a transition from generating energy to generating waste - in the form of decommissioned assets. Similarities are also evident in both industries in terms of the historical societal benefits and profits for the operator from the product, the long-term costs borne by the taxpayer for decommissioning and the challenge of costing decommissioning, with estimates for the UK's nuclear assets increasing over threefold to $>£ 150$ billion in the last 6 years (NDA, 2008, 2016). Chemical plants present many similar challenges in decommissioning as offshore hydrocarbon developments and integration of end-of-life issues into the design of new chemical plant have been proposed for some time (e.g. Hicks et al., 2000).

The mining sector has a long experience in dealing with the legacy of mining activities on land. Mine site reclamation has shifted from returning the site to as it was before the mining activity to making the best use of the land now for the nation and community. 101 Things to Do with a Hole in the Ground (Pearman, 2009) presents examples of solutions to problems caused by the legacy of mine closure. A range of outcomes are presented, showing old mines transformed into tourism attractions, wildlife habitats, sport and

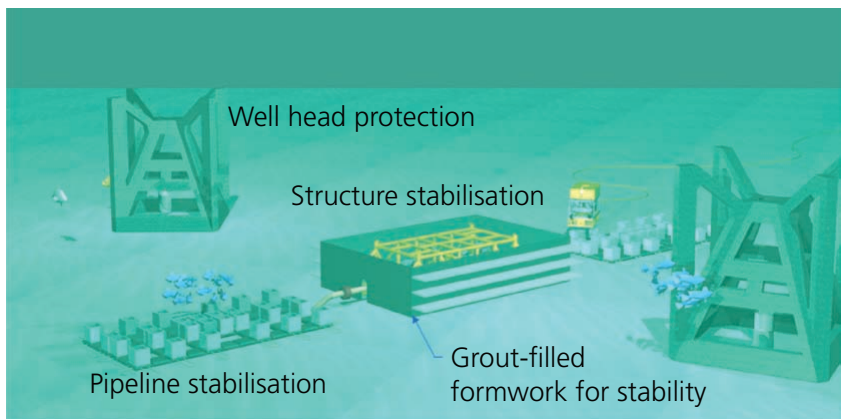

Figure 9. Potential augmentation of offshore infrastructure decommissioned in situ (image courtesy of Subcon Pty Ltd)

leisure facilities and dozens of industrial uses - demonstrating that the impacts of mining can be converted from liabilities to opportunities and benefits for local communities. Clear similarities exist with a rigs-to-reefs approach for the afterlife of decommissioned offshore infrastructure by way of transforming a liability on the private and public purse to an asset in the marine environment. The question could also be posed as to whether offshore oil and gas infrastructure decommissioned in situ would form part of industrial heritage in the future.

If offshore infrastructure is decommissioned in situ, consideration of augmentation to improve the marine science benefit should be considered. Engineered artificial reef modules can be used to augment the beneficial marine impact of the decommissioned infrastructure while also enhancing the structural stability for the afterlife as an artificial reef. Figure 9 illustrates an offshore hydrocarbon development, decommissioned in situ and augmented with a range of artificial reef structures. Grout-filled formwork provides stability to an overtrawl structure - and the fins protruding from the exterior are designed to encourage marine growth and a refuge for fish and other marine creatures. Likewise, a pipeline stabilisation mattress is augmented with upstands, designed to encourage marine growth and provide habitat for fish. Existing forms of artificial reef modules can also be deployed to augment in situ decommissioning of offshore infrastructure, as shown in Figure 9, providing well head protection.

The exemplars cited earlier indicate that the decommissioning burden will be eased if decommissioning is incorporated into design, and that can be achieved through legislated and consistent sector-wide commitment to reducing waste or environmental impact over the life cycle of the structure and optimising the endof-life outcome rather than trying to return a site to the condition before development. Design of next-generation offshore infrastructure should be guided by a range of alternative end-oflife options to enable optimal life-cycle outcomes.

\section{Concluding remarks}

This paper poses the questions 'What is the optimal end-of-life solution for decommissioned offshore infrastructure for a given 
context?' and 'How can the range of decommissioning options inform the design of next-generation offshore infrastructure to ease the financial and environmental end-of-life burden of offshore assets?' Four decommissioning options are identified: (a) complete removal, (b) partial removal and relocation offshore, (c) partial removal and in situ decommissioning and $(d)$ partial removal and in situ decommissioning with augmentation. Reasons why complete removal is often the default option and barriers to adoption of alternative options are discussed. The key findings and recommendations from the study are summarised in the following.

- The base case for complete removal of offshore infrastructure for decommissioning is borne out of law to protect against sea dumping (OSPAR Commission, 1998) and needs revisiting to enable alternative offshore decommissioning options more routinely.

- Aside from the absence of opportunity for the process, the scientific evidence base is insufficient to assess if complete removal and recycling or disposal onshore is the optimal outcome for offshore infrastructure. Complete removal is simply not compared with other decommissioning options for the vast majority of developments.

- The challenge for furthering the offshore decommissioning agenda is development of the scientific evidence base to justify the various alternatives - including and beyond complete removal; development of the technical innovations to facilitate those alternatives with minimum cost and risk; development of decision tools to determine the optimal solution for a given scenario - accounting for inputs across all sectors, stakeholders and the community - and development of processes and governance that provide clear and transparent pathways for decommissioning.

- Development of the evidence base requires consolidation of existing knowledge and future research across the physical, biological and social sciences.

- The scientific challenge must be addressed in order to develop smarter ways of decommissioning existing and future offshore infrastructure to minimise cost, risk and environmental impact of the end-of-field-life fate of offshore structures - either offshore or onshore - and maximise societal benefit.

- The scientific evidence base is required to underpin a decision framework to inform on and enable the most appropriate decommissioning option for a given location, marine environment and field architecture to deliver minimum cost, risk and environmental impact.

- A strategic plan is required to develop the evidence base and decision framework, achieve agreement on adoption of a consistent approach across the sector and gain public acceptance of the approach.

- A consistent industry-wide, or legislated, approach defining the framework and methodology for gathering and weighting data gathering across the sector could assist in clarifying expectations and streamlining the process for operators and regulators.

- Consideration of the entire life-cycle consequences of all decommissioning alternatives can minimise the risk of shifting negative impact across sectors and stakeholders. The exemplars cited in the paper indicate that the decommissioning burden will be eased if decommissioning is incorporated into design, and that can be achieved through legislated and consistent sector-wide commitment to reducing waste or environmental impact over the life cycle of the structure and optimising the end-of-life outcome rather than trying to return a site to the condition before development.

- Design of next-generation offshore infrastructure should be guided by a range of alternative end-of-life options to enable optimal life-cycle outcomes.

Populations around the globe have reaped the societal benefits of offshore energy production for decades and will continue to reap those benefits for decades into the future. The health and welfare of the current and future generations of those populations and of the planet are, and will be, equally affected by decisions made as to how to manage the asset base associated with current and future offshore energy production. It is too important a decision to put the onus on, or allow the opportunity to be directed by, any specific stakeholder. The industry, government and public have a collective responsibility and an opportunity to determine the process to lead to the 'best' endof-life outcome for the existing and future offshore energy asset base.

An opportunity exists, with the right evidence base, to transform decommissioning of offshore infrastructure from the current base case of complete removal, borne out of guidelines to prevent sea dumping, to a broader portfolio of options including in situ decommissioning with a view to minimising the life-cycle economic, environmental and societal impact of energy production. Decisions made now will influence which of the potential scenarios becomes the future reality and in turn will play a critical role in informing design of next-generation offshore infrastructure.

\section{Glossary of terms}

Decommissioning options - any option that can be used to decommission an infrastructure asset (specifically the options illustrated in Figure 6)

Decommissioning strategy - a strategy for implementing the chosen decommissioning option

Decommissioning plan - a plan to implement the chosen decommissioning option

Decommissioning alternatives - any decommissioning option that is not the default complete removal option

\section{REFERENCES}

Advisian (2017) A Scientific Literature Review: Environmental Impacts of Decommissioning Options. Advisian, Sydney, Australia. Arup (2014) Decommissioning in the North Sea-Review of Decommissioning Capacity. Arup, Edinburgh, UK. See http:// publications.arup.com/publications/d/decommissioning_in_the_north_sea. BSEE (US Bureau of Safety and Environmental Enforcement) (2018) Decommissioning Offshore Platforms. BSEE, Washington, DC, USA. 
See http://www.bsee.gov/Exploration-and-Production/Decomissioning/ index/ (accessed $02 / 10 / 2018$ )

CCC (Climate Change Capital) (2010) Offshore Renewable Energy Installation Decommissioning Study [Withdrawn]. Department of Energy and Climate Change, London, UK. See https://www.gov.uk/ government/publications/offshore-renewable-energy-installationdecommissioning-study (accessed 02/10/2018).

Chandler J, White DJ, Techera EJ, Gourvenec S and Draper S (2016) Engineering and legal considerations for decommissioning of offshore oil and gas infrastructure in Australia. Ocean Engineering 131 338-347, https://doi.org/10.1016/j.oceaneng.2016.12.030.

CIL NUS (Centre for International Law, National University of Singapore) (2013) Prospects for Large Scale Artificial Reefs in South East Asian Tropical Seas. CIL NUS, Singapore. See http://cil.nus.edu.sg/ programmes-and-activities/past-events/rigs-to-reefs-workshop/.

Claisse JT, Pondella DJ, Love M et al. (2014) Oil platforms off California are among the most productive marine fish habitats globally. Proceedings of the National Academy of Sciences of the United States of America 111(43): 15462-15467, https://doi.org/10.1073/pnas.1411477111.

CPA (Norwegian Climate and Pollution Agency) (2011) Decommissioning of Offshore Installations. CPA, Oslo, Norway.

Cullinane B and Gourvenec S (2017) Decommissioning - the next Australian oil and gas boom? APPEA Journal 57(2): 421-425, https://doi.org/10.1071/AJ16203.

Defra (Department for Environment, Food and Rural Affairs) (2011) Guidance on Applying the Waste Hierarchy. Defra, London, UK. See https://www.gov.uk/government/uploads/system/uploads/attachment_data/ file/69403/pb13530-waste-hierarchy-guidance.pdf (accessed 02/10/2018).

DRET (Department of Resources, Energy and Tourism) (2008) Decommissioning Australia's Offshore Oil and Gas Facilities: a Discussion Paper. Dret, Canberra, Australia.

EC (European Community) (2000) Directive 2000/53/EC of the European Parliament and of the Council of 18 September 2000 on end-of life vehicles. Official Journal of the European Communities L269.

EC (2008) Waste Framework Directive (2008/98/EC) European Parliament and of the Council of 19 November 2008 on waste and repealing certain Directives. Official Journal of the European Communities L312/3. See http://eur-lex.europa.eu/legal-content/EN/TXT/? uri=CELEX:32008L0098 (accessed 02/10/2018).

Ekins P, Vanner R and Firebrace J (2005) Decommissioning of Offshore Oil and Gas Facilities: Decommissioning Scenarios: a Comparative Assessment Using Flow Analysis. Policy Studies Institute, London, UK. See http://www.psi.org.uk/docs/2005/UKOOA/DecommissioningWorking\%20paper.pdf (accessed 03/10/2018).

Fowler AM, Macreadie PI, Jones DOB and Booth DJ (2014) A multicriteria decision approach to decommissioning of offshore oil and gas infrastructure. Ocean \& Coastal Management 87: 20-29, https://doi. org/10.1016/j.ocecoaman.2013.10.019.

Foxwell D (2016) Decom market growing in size and complexity but providers 'too fragmented'. Offshore Support Journal, 2 December. See http://www.osjonline.com/news/view,decom-market-growing-insize-and-complexity-but-providers-too-fragmented_45672.htm (accessed 03/10/2018).

Gourvenec S (2017) Next generation offshore infrastructure. Proceedings of the 5th International Conference on Next Generation Infrastructure (ISNGI), London, UK, pp. 162-171. See http://isngi.org/wp-content/ uploads/2017/10/ISNGI-Conference-Proceedings-v2.pdf (accessed 03/10/2018).

Gourvenec S and Techera EJ (2016) Rigs to Reefs: Is It Better to Leave Disused Oil Platforms Where They Stand? The Conversation, Parkville, Australia. See https://theconversation.com/rigs-to-reefs-is-itbetter-to-leave-disused-oil-platforms-where-they-stand-63670 (accessed 03/10/2018).

Gourvenec S and White DJ (2017) In situ decommissioning of subsea infrastructure. Proceedings of the Conference of Offshore and
Maritime Engineering; Decommissioning of Offshore Geotechnical Structures, Hamburg, Germany, keynote 3-40.

GWEC (Global Wind Energy Council) (2017) Global Wind 2017 Report: a Snapshot of Top Wind Markets in 2017: Offshore Wind. GWEC, Brussels, Belgium. See http://gwec.net/wp-content/uploads/2018/04/ offshore.pdf (accessed 03/10/2018).

Hess (2014) Fife, Fergus, Flora and Angus Fields Decommissioning Programmes: Close-out Report. Hess, New York, NY, USA. See http://www.hess.com/docs/default-source/sustainability/fffa-close-outreport.pdf?sfvrsn=2 (accessed 03/10/2018).

Hicks DI, Crittenden BD and Warhurst AC (2000) Design for decommissioning - addressing the future closure of chemical sites in the design of new plant. Process Safety and Environmental Protection 78(6): 465-479, https://doi.org/10.1205/095758200531014.

IMO (International Maritime Organization) (1989) Guidelines and Standards for the Removal of Offshore Installations and Structures on the Continental Shelf and in the Exclusive Economic Zone (IMO Resolution A. 672 (16)). See http://www.imo.org/environment/ mainframe.asp?topic_id=1026 (accessed 12/10/2018).

Insite (Influence of Man-made Structures in the Ecosystem) (2018) http:// www.insitenorthsea.org/about/ (accessed 02/10/2018).

Jambeck J, Geyer R, Wilcox C et al. (2015) Plastic waste inputs from land into the ocean. Science 347(6223): 768-771, https://doi.org/10.1126/ science. 1260352 .

Jørgensen D (2012) OSPAR's exclusion of rigs-to-reefs in the North Sea. Ocean \& Coastal Management 58: 57-61, https://doi.org/10.1016/j. ocecoaman.2011.12.012.

Kaiser MJ and Snyder B (2012) Modeling the decommissioning cost of offshore wind development on the U.S. Outer Continental Shelf. Marine Policy 36(1): 153-164, https://doi.org/10.1016/j.marpol.2011. 04.008 .

Lempriere M (2017) Full Circle: Decommissioning the First Ever Offshore Windfarm. Power Technology, London, UK. See https:// www.power-technology.com/features/full-circle-decommissioning-firstever-offshore-windfarm/ (accessed 03/10/2018).

Macreadie PI, Fowler AM and Booth DJ (2011) Rigs-to-reefs: will the deep sea benefit from artificial habitat? Frontiers in Ecology and the Environment 9(8): 455-461, https://doi.org/10.1890/100112.

MarEx (Maritime Executive) (2015) Pioneering Spirit: World's Largest Vessel Nears Completion. MarEx, Fort Lauderdale, FL, USA. See http://www.maritime-executive.com/article/pioneering-spirit-worldslargest-vessel-nears-completion (accessed 02/10/2018).

MarEx (2016) The First Offshore Wind Farm Decommissioning Complete. MarEx, Fort Lauderdale, FL, USA.

Maslin E (2016) Up against OSPAR. Offshore Engineer, December. See http://www.oedigital.com/regions/europe/item/14058-up-against-ospar (accessed 03/10/2018).

McLean DL, Partridge JC, Bond T et al. (2017) Using industry ROV videos to assess fish associations with subsea pipelines. Continental Shelf Research 141: 76-97, https://doi.org/10.1016/j.csr.2017.05.006.

Melchers RE (2006) Examples of mathematical modelling of long term general corrosion of structural steels in sea water. Corrosion Engineering, Science and Technology 41(1): 38-44, https://doi.org/10. 1179/174327806X93992.

NDA (Nuclear Decommissioning Authority) (2008) Annual Report \& Accounts 2007/08. The Stationery Office, London, UK. See https:// www.gov.uk/government/publications/nuclear-decommissioningauthority-annual-report-and-accounts-2007-to-2008 (accessed 03/10/ 2018).

NDA (2016) Nuclear Provision: the Cost of Cleaning Up Britain's Historic Nuclear Sites. Government Digital Service, London, UK. See https://www.gov.uk/government/publications/nuclear-provisionexplaining-the-cost-of-cleaning-up-britains-nuclear-legacy/nuclearprovision-explaining-the-cost-of-cleaning-up-britains-nuclearlegacy\#latest-estimate (accessed 03/10/2018). 
Nera (National Energy Resources Australia) (2016) Oil \& Gas Industry Competitiveness Assessment, Report on the Framework, Baseline Score, Insights and Opportunities, September 2016. Nera, Sydney, Australia. See http://www.nera.org.au/Chapter?Action=View\&Chapter $\mathrm{id}=9$.

Oil \& Gas UK (2016) Decommissioning Insight 2016. Oil \& Gas UK, Aberdeen, UK. See http://oilandgasuk.co.uk/wp-content/uploads/2016/ 11/Decommissioning-Insight-2016-Oil-Gas-UK.pdf (accessed 03/10/ 2018).

Oil and Gas Authority (2016) Decommissioning Strategy. Oil and Gas Authority, Aberdeen, UK. See https://www.ogauthority.co.uk/newspublications/publications/2016/decommissioning-strategy/ (accessed 03/10/2018).

OSPAR (Oslo/Paris Convention) Commission (1998) Decision 98/3 on the Disposal of Disused Offshore Installations. OSPAR Commission, London, UK. See http://www.ospar.org/convention/text (accessed 03/ 10/2018).

Paik JK and Melchers RE (2014) Condition Assessment of Aged Structures. Woodhead Publishing, Cambridge, UK.

Parente V, Ferreira D, Moutinho dos Santos E and Luczynski E (2006) Offshore decommissioning issues: deductibility and transferability. Energy Policy 34(15): 1992-2001, https://doi.org/10.1016/j.enpol. 2005.02.008

Pearman G (2009) 101 Things to Do with a Hole in the Ground. PostMining Alliance/Eden Project, Cornwall, UK.

RAEng (Royal Academy of Engineering) (2013) Decommissioning in the North Sea. RAEng, London, UK. See http://www.raeng.org.uk/ publications/reports/decommissioning-in-the-north-sea (accessed 03/10/2018)

Reisser J, Shaw J, Wilcox C et al. (2013) Marine plastic pollution in water around Australia: characteristics, concentrations, and pathways. PLOS ONE 8(11): e80466, https://doi.org/10.1371/journal.pone.008046.

Richert C, Rogers A and Burton M (2015) Measuring the extent of a social license to operate: the influence of marine biodiversity offsets in the oil and gas sector in Western Australia. Resources Policy 43: 121-129, https://doi.org/10.1016/j.resourpol.2014.12.001.

Rogers A and Burton M (2017) Social preferences for the design of biodiversity offsets for shorebirds in Australia. Conservation Biology 31(4): 828-836, https://doi.org/10.1111/cobi.12874.

Rosen J, Jayasinghe K, Potts A, Melchers R and Chaplin R (2015) SCORCH JIP - Findings from investigations into mooring chain and wire rope corrosion in warm waters. Proceedings of the Offshore Technology Conference, Houston, TX, USA, document OTC-26017-MS.

RSA (Royal Society for the encouragement of Arts, Manufactures and Commerce) (2015) North Sea Oil and Gas Rig Decommissioning \& Re-use Opportunity Report. RSA, London, UK. See https://www. thersa.org/globalassets/pdfs/reports/rsa-great-recovery - north-sea-oiland-gas-report.pdf (accessed 03/10/2018).

Russell T (2016) Nuon Decommissions Lely Wind Farm. 4C Offshore, Lowestoft, UK. See http://www.4coffshore.com/windfarms/nuondecommissions-lely-wind-farm-nid4591.html (accessed 03/10/2018).

Scott ME, Smith JA, Lowry MB, Taylor MD and Suthers IM (2015) The influence of an offshore artificial reef on the abundance of fish in the surrounding pelagic environment. Marine Freshwater Research 66(5): 429-437, https://doi.org/10.1071/MF14064.

Shell (2017) http://www.shell.co.uk/sustainability/decommissioning/brentfield-decommissioning/brent-field-decommissioning-programme.html (accessed 03/10/2018).

Techera E and Chandler J (2015) Offshore installations, decommissioning and artificial reefs: do current legal frameworks best serve the marine environment? Marine Policy 59: 53-60, https://doi.org/10.1016/j. marpol.2015.04.021.

Topham E and McMillan D (2017) Sustainable decommissioning of an offshore wind farm. Renewable Energy 102: 470-480, https://doi.org/ 10.1016/j.renene.2016.10.066.

Wamsi (West Australian Marine Science Institute) (2016) Independent Review of the Effects of Decommissioning Offshore Infrastructure. Wamsi, Crawley, UK.

Wamsi (2017) Decommissioning Offshore Infrastructure: a Review of Stakeholder Views and Science Priorities. Wamsi, Crawley, UK.

WindEurope (2017) Wind Energy in Europe: Outlook to 2020. WindEurope, Brussels, Belgium. See https://windeurope.org/aboutwind/reports/wind-energy-in-europe-outlook-to-2020/ (accessed 03/10/ 2018).

Wood Mackenzie (2016) https://www.woodmac.com/reports/upstream-oiland-gas-decommissioning-asia-pacific-600-fields-on-the-front-line43747368 (accessed 28/02/2017).

World Energy Council (2016) World Energy Resources - Wind 2016. World Energy Council, London, UK. See https://www.worldenergy. org/wp-content/uploads/2017/03/WEResources_Wind_2016.pdf (accessed 03/10/2018)

\section{How can you contribute?}

To discuss this paper, please email up to 500 words to the editor at journals@ice.org.uk. Your contribution will be forwarded to the author(s) for a reply and, if considered appropriate by the editorial board, it will be published as discussion in a future issue of the journal.

Proceedings journals rely entirely on contributions from the civil engineering profession (and allied disciplines). Information about how to submit your paper online is available at www.icevirtuallibrary.com/page/authors, where you will also find detailed author guidelines. 